\title{
Multi responses optimization of wire EDM process parameters using Taguchi approach coupled with principal component analysis methodology
}

\author{
Anil Kumar Dhakad ${ }^{1 *}$, Jyoti Vimal ${ }^{2}$ \\ ${ }^{1,2}$ Department of Mechanical Engineering, Madhav Institute of Technology \& Science Gwalior (M.P.), 474005 INDIA \\ Corresponding Author's E-mail: anilkumardhakad007@gmail.com, Tel.: 7828722765
}

\begin{abstract}
The wire EDM was known as for its better efficiency to machining hardest material and give precise and accurate result comparing to other machining process. The intent of this experimental paper is to optimize the machining parameters of Wire Electrical Discharge Machining (WEDM) on En45A Alloy Steel with the approach of Principal component Analysis (PCA). Three control variables Open Voltage (OV), Servo Voltage (SV), \& Wire Feed (WF) are considered in this study to see their effect on three responses ie. Metal Removal Rate (MRR), Machining Time (MT) and Gap voltage (GV). The experiment has been conducted as per Taguchi's $\mathrm{L}_{9}$ Orthogonal Array (OA). The Total principal component index (TPCI) is find out by using PCA methodology. There after ANOVA is applied to find out the percentage contribution of the process variables. It has been found that the open voltage $(\mathrm{OV})$ is the most effecting variable on multiple responses.
\end{abstract}

Keywords: En45A alloy steel, wire electrical discharge machining (WEDM), Taguchi's orthogonal array (OA), Principal component analysis (PCA), ANOVA

DOI: http://dx.doi.org/10.4314/ijest.v9i2.6

\section{Introduction}

Today's age is an industrial age. Now-a-days, many industries are using soft and hard materials to manufacture the product. To cut those hardest materials with precise dimension in minimum time, for this Wire Electrical Discharge Machine is used as Hotelling (1933). Globally, wire EDM is use as a machine tool for harder material which requires high strength and hardness, while the traditional manufacturing process needs some special tool or modern technique with a longer working time. WEDM is non-traditional, non-conventional, thermoelectric machining process which erodes material from work piece with the help of spark, which is generated between work piece and wire (tool electrode) immersed in liquid dielectric medium (distilled water). In this electric discharge melt and vaporize the material which is ejected and flushed out by the fluid is in Pearson paper (1901). WEDM is also capable to perform operation on taper angle by applying a relative movement between the upper and lower guides. Wire EDM is a 5 axis $(\mathrm{X}, \mathrm{Y}, \mathrm{Z}, \mathrm{U}, \& \mathrm{~V})$ machine in which $\mathrm{U} \& \mathrm{~V}$ axis are used for taper cutting. As Kumar et al. (2015) stated that in wire EDM wire is used as an electrode which is made up of brass, titanium, copper, and tungsten of diameter 0.05 to 0.30 $\mathrm{mm}$. The machine on which I conduct experiments, $0.25 \mathrm{~mm}$ diameter brass wire is used because of its small diameter it is capable of achieving very small corner radius. Mohapatra and Sahoo (2015) identified the gap between work piece and wire tool during machine operation is in micron.

\section{Literature Review}

Paiva et al. (2007) an alternative hybrid approach, while combining PCA and RSM are used form optimizing cutting speed, depth of cut, and feed rate as a processing parameters and finally conclude that cutting speed $238 \mathrm{~m} / \mathrm{min}$, with a feed rate of $0.08 \mathrm{~mm} / \mathrm{rev}$ and depth of cut $0.32 \mathrm{~mm}$ are as optimal parameter on which maximum MRR at minimum surface roughness. V. 
Jaiganesh and Raju (2008) solve the problem in product selection or product design is to selection of parameters, levels for optimizing multiple responses and finally they find out the optimal parameters on which MRR, SF, kerfs can be measured. Singh and Garg (2009) the effect of multiple parameters of WEDM like pulse on time, pulse off time, wire feed, gap voltage, wire tension and peak current on MRR while applying on Hot die steel (H-11) have been calculated and provide the optimal parameter on which maximum MRR can be achieved. Siddiquee et al. (2008) presented an application of centerless cylindrical grinding process of operation for IC engine, with the help grey relational analysis coupled with principal component analysis. Gopalsamy et al. (2009) Here Taguchi's technique is applied for finding optimal processing parameters while machining hardened material and finally Taguchi's result is very close to the result of ANOVA method and on CS $204 \mathrm{~m} / \mathrm{min}$, Feed $0.2 \mathrm{~mm} /$ tooth, DOC $0.2 \mathrm{~mm}$ and WOC $0.2 \mathrm{~mm}$ are the optimal parameters. Lahane et al. (2012) optimize the multi-responses of WEDM using principal component analysis while they considered pulse on, pulse off, upper flush, wire feed and finally provide the optimal parameters on which maximum MRR and minimum WWR of HSS material.

Dharmender et al. (2012) investigated the effect of process parameters on surface roughness (SR) on WEDM while considering input parameters peak current, pulse on time, pulse off time \& wire tension for En31 tool steel material and concluded the error between experimental and predicted values for surface roughness (SR) is 5.67\%. Paul and Sumam (2012) this research paper they build face recognition system by applying principal component analysis (PCA) technique and Eigen face approach. The system can successfully recognized the human faces and it can easily work in different face orientation. Prajapati and Patel (2013) cutting rate and surface roughness, the pulse ON, pulse OFF are most significant part of optimizing and spark gap is significant for kerfs width. Rajyalakshmi and Ramaiah (2013) discussed the application of the Taguchi method coupled with fuzzy logic to optimize the machining parameters of WEDM and finally conclude the optimal parameter on which MRR \& MRPI are maximum at minimum SR and spark gap. Raghuraman et al. (2013) had done optimization of EDM parameters using Grey relational analysis with Taguchi approach for mild steel IS 2026 and they concluded optimal parameters combination as A3B2C1. Rao and Selvaraj (2013), performed their operation on wire EDM and considered Pulse ON time, Pulse OFF time, Peak current, Wire tension, Wire voltage, Servo feed rate as a optimizing parameters for Titanium Alloy material and investigate the effects of process parameters on MRR and SR. Singh and Sharma (2013) they worked on WEDM to optimize the process parameters and improved the machining quality. Theirs input process parameters are Pulse on time, Servo voltage, Pulse off time, Peak current, Wire tension and Wire feed are as input parameters and finally they concluded maximum MRR at minimum surface roughness with the help of MINITAB software. Das et al. (2014) investigate the machining process parameter of WEDM for multi-responses on EN31 tool steel using WPCA and finally optimal result is verified through confirmatory test. Nayak and Mahapatra (2014) optimize the part thickness, pulse duration, taper angle, wire tension and discharge current as processing parameters and investigate the optimal parameter. In this paper they show the importance of WEDM while using taper angle. Chandgude et al. (2015) investigated the optimal processing parameter of end milling machine while machining on AISI D2 hardened steel using principal component analysis on Taguchi orthogonal array. Gupta et al. (2015) hybrid approach of Taguchi and principal component analysis was applied while welding two dissimilar material AA5083-O and AA6063-T6 aluminium alloys. ANOVA results shows that tool rotational speed (35.37\%) and welding speed (35.61\%) are almost equal process parameter for TPCI.

\section{Investigative procedure}

In the current work, in order to optimize the process parameters, the following procedure prevails: (1) Selection of modern Wire EDM to perform trails; (2) Selection of material according to importance and machining cost; (3) Find out the levels for selected process parameters; (4) Selection of Taguchi $\mathrm{L}_{9}$ orthogonal array; (5) Implement parameters as per the selected orthogonal array; (6) Record the responses characteristics; (7) Normalizing the responses values; (8) Identify the optimal conditions for Wire EDM for En45A alloy steel; (9) ANOVA is conducted to find out the parameters percentage contribution.

\section{Proposed methodology: Principal component analysis}

Initially, with the help of Taguchi's methodology $\mathrm{L}_{9}$ orthogonal array is created (Chalisgonkar, 2014). Open Voltage (OV), Servo voltage (SV) and Wire feed (WF) considered as an optimizing parameters for WEDM for machining En45A alloy steel material which is shown in Table 2 .

Here, on various process parameters, machining operation was conducted on our En45A alloy steel material and responses are recorded for individual trail. We considered Material Removal Rate (MRR), Machining Time (MT) and Gap Voltage (GV) as responses in Table 4.

Step 1 Array of responses during machining (Paiva et al., 2007) 


$$
\mathrm{A}=\left[\begin{array}{ccc}
x_{11} & \ldots & x_{1 v} \\
& \cdot & \\
& \cdot & \\
x_{u 1} & \ldots & x_{u v}
\end{array}\right]
$$

Where $u$ is the number of trails and $v$ is the number of responses, $A$ is an array of responses.

Step 2 Convert into S/N ratio

Now, responses are converted into the signal to the noise $(\mathrm{S} / \mathrm{N})$ ratio with the help of equation $1 \& 2$ as shown in Table 5 . Machining time and gap voltage are converted through "lower-the-better" equation 1 and for material removal rate "higher-thebetter" equation 2 is used (Mohapatra and Sahoo, 2015).

For Lower-the-better (LB),

$$
(S / N)_{L B}=-10 \log _{10}\left[\frac{1}{v} \sum_{u=1}^{v} v x_{u v}^{2}\right]
$$

For Higher-the-better (HB),

$$
(S / N)_{H B}=10 \log _{10}\left[\frac{1}{v} \sum_{u=1}^{v} \frac{1}{x_{u v}^{2}}\right]
$$

where $x$ is responses value, $\mathrm{u}$ and $\mathrm{v}$ are experimental condition.

Step 3 Normalization of $\mathrm{S} / \mathrm{N}$ ratios values

Now, $\mathrm{S} / \mathrm{N}$ ratio values are normalized with the help of equation $3 \& 4$. Normalized values will lies between $0-1$ which is in table 6.

For Lower-the-better (LB),

$$
Z=\frac{\operatorname{Max}\left(x_{u v}\right)-x_{u v}}{\operatorname{Max}\left(x_{u v}\right)-\operatorname{Min}\left(x_{u v}\right)}
$$

For Higher-the-better (HB),

$$
Z=\frac{x_{u v}-\operatorname{Min}\left(x_{u v}\right)}{\operatorname{Max}\left(x_{u v}\right)-\operatorname{Min}\left(x_{u v}\right)}
$$

where $\mathrm{Z}$ is the normalised value for $\mathrm{x}_{\mathrm{uv}}$ responses, Min $\left(\mathrm{x}_{\mathrm{uv}}\right)$ is the smallest value of $\mathrm{x}_{\mathrm{uv}}$ and Max $\left(\mathrm{x}_{\mathrm{uv}}\right)$ is the largest value of $\mathrm{x}_{\mathrm{uv}}, \mathrm{Z}$ is a normalized array.

$$
\mathrm{Z}=\left[\begin{array}{ccc}
z_{11} & \cdots & z_{1 v} \\
& \cdot & \\
& \cdot & \\
z_{u 1} & \cdots & z_{u v}
\end{array}\right]
$$

Step 4 calculate variance-covariance in array B through the normalized values 


$$
\begin{gathered}
\mathrm{B}=\left[\begin{array}{ccc}
N_{11} & \cdots & N_{1 v} \\
& \cdot & \\
N_{u 1} & \cdots & N_{u v}
\end{array}\right] \\
\mathrm{N}_{\mathrm{u}, \mathrm{v}}=\frac{\operatorname{Cov}(x(u), x(v))}{\sqrt{\operatorname{Var}(x(u))^{*} \operatorname{Var}(x(v))}}
\end{gathered}
$$

where $\mathrm{u}=1,2,3, \ldots, \mathrm{v}$, and $\operatorname{Cov}(\mathrm{x}(\mathrm{u}), \mathrm{x}(\mathrm{v}))$ is the covariance of $\mathrm{x}(\mathrm{u})$ and $\mathrm{x}(\mathrm{v})$.

Step 5 Calculate the Eigen values and Eigen vectors with the help of correlation coefficient,

Calculate the Eigen values and Eigen vectors with the help of variance and covariance using equation 5. Eigen values and Eigen vectors are in Table 7. Now find out the correlation coefficient through equation 6.

$$
\left(\mathrm{R}-\lambda_{\mathrm{x}} \mathrm{I}_{\mathrm{u}}\right) \mathrm{V}_{\mathrm{uv}}=0
$$

where $\mathrm{R}$ is correlation, $\lambda$ is Eigen value, $\mathrm{I}$ is identity matrix and $\mathrm{V}$ is Eigen vectors.

Step 6 Find the principal components,

Next step is to calculate principal component which can be seen in Table 8.

$$
\mathrm{PC}_{\mathrm{i}}=\sum_{x=1}^{v} x_{u v} * V_{u v}
$$

where $i=1,2,3, \ldots, n$

Step 7 Calculate the Total Principal Component Index,

Total principal component index is calculated which provide the best solution or process parameter on which material removal rate is maximum and machining time and gap voltage are minimum, in Table 9.

$$
\mathrm{TPCI}_{i}=\sum_{x=1}^{v} P C_{i} * e(x)
$$

where, $\mathrm{e}(\mathrm{x})=\frac{\operatorname{eig}(x)}{\sum_{x=1}^{v} \operatorname{eig}(x)}$

eig $(x)=x^{\text {th }}$ Eigen value

Step 8 Generate response table and choose the optimal processing parameters.

\begin{tabular}{|c|c|c|c|}
\hline Variables & Level 1 & Level 2 & Level 3 \\
\hline Open Voltage (OV) & $\mathrm{m}_{1}$ & $\mathrm{~m}_{2}$ & $\mathrm{~m}_{3}$ \\
\hline Servo Voltage (SV) & $\mathrm{n}_{1}$ & $\mathrm{n}_{2}$ & $\mathrm{n}_{3}$ \\
\hline Wire Feed (WF) & $\mathrm{o}_{1}$ & $\mathrm{o}_{2}$ & $\mathrm{o}_{3}$ \\
\hline
\end{tabular}

$$
\mathrm{m}_{1}==\frac{(T P C I)^{1}+(T P C I)^{2}+(T P C I)^{2}}{3}
$$




$$
\begin{aligned}
& \mathrm{n}_{1}==\frac{(T P C I)^{1}+(T P C I)^{4}+(T P C I) 7}{3} \\
& \mathrm{o}_{1}==\frac{(T P C I)^{1}+(T P C I)^{6}+(T P C I)^{8}}{3}
\end{aligned}
$$

Step 9 Now ANOVA is carried out to find the percentage contribution of process parameters, which make it easy to identify most effecting parameter.

\section{Experimental Setup}

\subsection{Machine setup}

Wire EDM was invented in 1967 in USSR by David H. Dulebohn's group, for making tools from hardened steel. These trails are conducted on 5 axis $(\mathrm{X}, \mathrm{Y}, \mathrm{Z}, \mathrm{U}, \mathrm{V})$ computer numerical control (CNC) Wire EDM machine which was developed by master cam, Taiwan company in 2012 which is situated at Micro, Small and Medium Enterprises (MSME) Agra (U.P.). In this machine brass wire of $0.25 \mathrm{~mm}$ diameter is used as a cutting tool (electrode). This machine contains various input parameters as open voltage, pulse on time, pulse off time, servo voltage, wire tension, wire feed, water flow rate etc. and output parameters as gap voltage, cutting speed, etc.

Specification of machine

- Table size : $740 x 400 \mathrm{~mm}$

- Maximum height of workpiece : $295 \mathrm{~mm}$

- Maximum width of workpiece : $295 \mathrm{~mm}$

- Maximum machine speed $: 250 \mathrm{~mm}^{2} / \mathrm{min}$

- Total AC power input : 220 phase

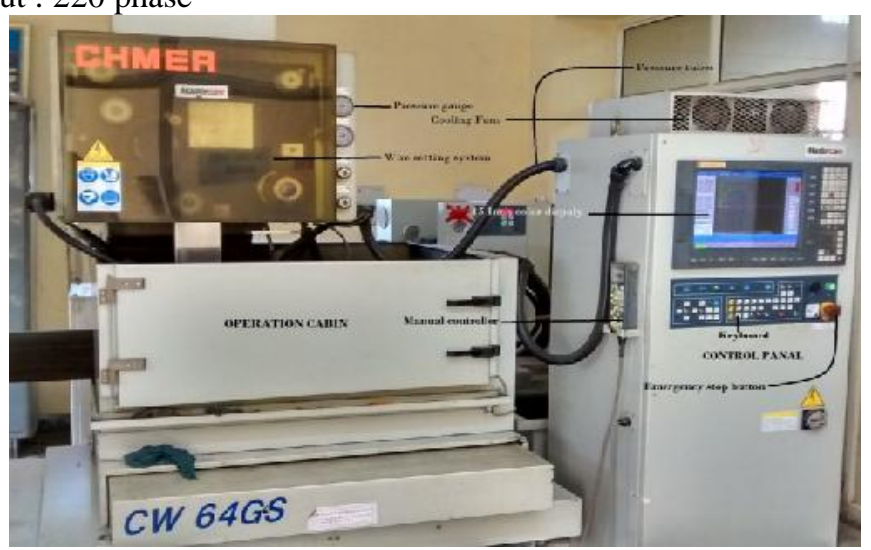

Figure 1. Machine setup

\subsection{Selection of material}

We selected En45A alloy steel as workpiece for our experimental work. It is widely used in most of the field for manufacturing of oil and gases pipeline, springs, construction, automobiles and power plants as Danial Ghodsiyeh, Abolfazl Golshan and Jamal Azimi Shirvanehdeh (2013) described. It is widely used due to its mechanical properties and hardness. Melting temperature of En $45 \mathrm{~A}$ alloy steel is $1425^{\circ} \mathrm{c}$ and its density is $8.08 \mathrm{gm} / \mathrm{cm}^{3}$. Chemical compositions of En $45 \mathrm{~A}$ alloy steel material are as below shown in Table 1 (Durairaj et al., 2014).

Table 1. Chemical composition of En45A alloy steel

\begin{tabular}{|c|c|c|c|c|c|c|}
\hline Elements & Carbon (C) & Silicon (Si) & $\begin{array}{c}\text { Manganese } \\
(\mathbf{M n})\end{array}$ & $\begin{array}{c}\text { Chromium } \\
(\mathbf{C r})\end{array}$ & $\begin{array}{c}\text { Copper } \\
(\mathbf{C r})\end{array}$ & Iron (Fe) \\
\hline$\%$ & 0.66 & 1.62 & 0.89 & 0.23 & 0.20 & 95.60 \\
\hline
\end{tabular}



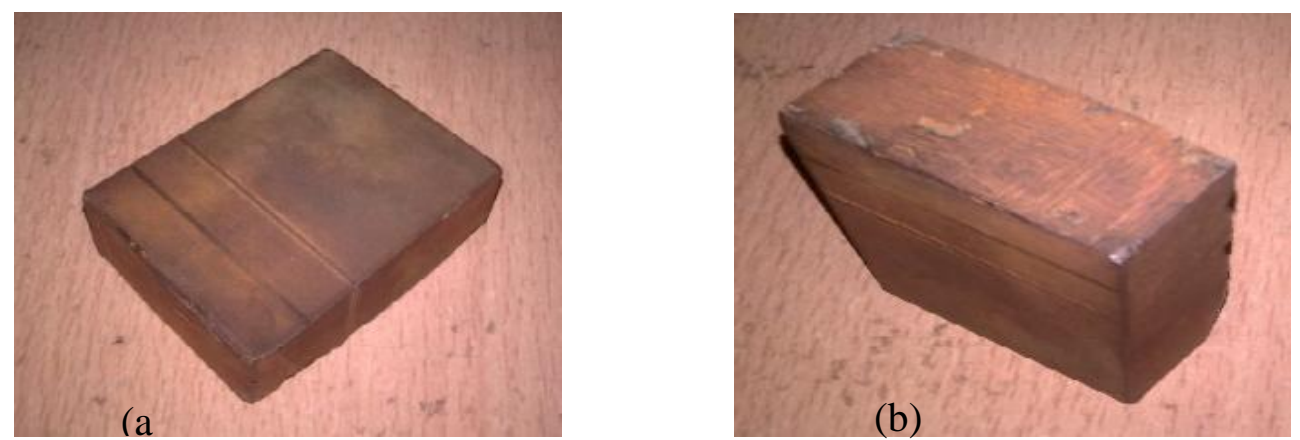

Figure 2. Top view (a) and side view (b) of En45A Alloy steel material

Table 2. Variables with their levels

\begin{tabular}{|c|c|c|c|c|c|c|}
\hline S. No & Variables & Symbols & Units & Level $\left(\mathbf{L}_{\mathbf{1}}\right)$ & Level $\left(\mathbf{L}_{\mathbf{2}}\right)$ & Level $\left(\mathbf{L}_{\mathbf{3}}\right)$ \\
\hline 1. & Open Voltage (OV) & A & Volts & 80 & 85 & 90 \\
\hline 2. & Servo Voltage (SV) & B & Volts & 30 & 40 & 50 \\
\hline 3. & Wire Feed (WF) & C & m/min & 5 & 6 & 7 \\
\hline
\end{tabular}

This technique is found by Genichi Taguchi, a Japanese scientist which is based on orthogonal array (Rao and Selvaraj, 2013). Nowever day it is widely using day by day it makes trails compact and make less difficult to find out the optimal parameters. This technique is totally depends on factors and number of trails (level). Here we consider $\mathrm{L}_{9}$ Taguchi orthogonal array for which our input parameters are Open voltage (OV), Servo voltage (SV), and Wire feed (WF) (following Lokesh et al., 2015). Taguchi $\mathrm{L}_{9}$ orthogonal array is shown in Table 3.

Table 3. Taguchi $\mathrm{L}_{9}$ orthogonal array

\begin{tabular}{|c|c|c|c|}
\hline Trails & Open Voltage (A) & Servo Voltage (B) & Wire Feed (C) \\
\hline 1 & 1 & 1 & 2 \\
\hline 2 & 1 & 2 & 3 \\
\hline 3 & 1 & 3 & 2 \\
\hline 4 & 2 & 1 & 3 \\
\hline 5 & 2 & 2 & 1 \\
\hline 6 & 2 & 3 & 3 \\
\hline 7 & 3 & 1 & 1 \\
\hline 8 & 3 & 2 & 2 \\
\hline 9 & 3 & 3 & \\
\hline
\end{tabular}

Table 4. Table of experimental responses

\begin{tabular}{|c|c|c|c|}
\hline Trails & $\begin{array}{c}\text { Material Removal Rate } \\
(\mathbf{M R R})\left(\mathbf{m m}^{\mathbf{3}} \mathbf{m i n}\right)\end{array}$ & $\begin{array}{c}\text { Machining Time (MT) } \\
(\mathbf{m i n})\end{array}$ & $\begin{array}{c}\text { Gap Voltage }(\mathbf{G V}) \\
(\text { Volts })\end{array}$ \\
\hline 1 & 78.9600 & 5.2160 & 30.3400 \\
\hline 2 & 62.8800 & 6.4500 & 38.9600 \\
\hline 3 & 55.1200 & 7.3170 & 48.5200 \\
\hline 4 & 79.6000 & 5.1170 & 30.2000 \\
\hline 5 & 65.9200 & 6.1670 & 37.8400 \\
\hline 6 & 51.2000 & 7.9000 & 50.6900 \\
\hline 7 & 75.6000 & 5.4000 & 30.5200 \\
\hline 8 & 58.3200 & 6.9500 & 42.1200 \\
\hline 9 & 49.2800 & 8.2170 & 51.2300 \\
\hline
\end{tabular}

Table 5. Sequences of S/N ratio

\begin{tabular}{|c|c|c|c|}
\hline Trails & S/N (MRR) (dB) & S/N (MT) (dB) & S/N (GV) (dB) \\
\hline 1 & 37.9481 & -14.3467 & -29.6403 \\
\hline 2 & 35.9702 & -16.1912 & -31.8124 \\
\hline 3 & 34.8262 & -17.2867 & -33.7184 \\
\hline 4 & 38.0183 & -14.1803 & -29.6001 \\
\hline 5 & 36.3803 & -15.8015 & -31.5590 \\
\hline
\end{tabular}


Table 5 (Cont'd). Sequences of S/N ratio

\begin{tabular}{|c|c|c|c|}
\hline Trails & S/N (MRR) (dB) & S/N (MT) (dB) & S/N (GV) (dB) \\
\hline 6 & 34.1854 & -17.9525 & -34.0984 \\
\hline 7 & 37.5704 & -14.6479 & -29.6917 \\
\hline 8 & 35.3163 & -16.8397 & -32.4898 \\
\hline 9 & 33.8534 & -18.2943 & -34.1905 \\
\hline
\end{tabular}

Table 6. Normalized $\mathrm{S} / \mathrm{N}$ ratio values

\begin{tabular}{|c|c|c|c|}
\hline Trails & Normalized (MRR) & Normalized (MT) & Normalized (GV) \\
\hline 1 & 0.9832 & 0.0405 & 0.0012 \\
\hline 2 & 0.5083 & 0.4888 & 0.4744 \\
\hline 3 & 0.2336 & 0.7551 & 0.8897 \\
\hline 4 & 1.0000 & 0.0000 & 0.0000 \\
\hline 5 & 0.6067 & 0.3941 & 0.4192 \\
\hline 6 & 0.0797 & 0.9169 & 1.0000 \\
\hline 7 & 0.8925 & 0.1136 & 0.0124 \\
\hline 8 & 0.3513 & 0.6464 & 0.6220 \\
\hline 9 & 0.0000 & 1.0000 & 0.9925 \\
\hline
\end{tabular}

Table 7. Eigen values \& Eigen vectors

\begin{tabular}{|l|c|c|c|}
\hline & PC1 & PC2 & PC3 \\
\hline Eigen Vectors & -0.4780 & 0.373 & 0.726 \\
\hline & 0.4780 & -0.441 & 0.687 \\
\hline & 0.476 & 0.816 & -0.039 \\
\hline Eigen Values & 2.9882 & 0.0116 & 0.0002 \\
\hline Proportion & 0.9960 & 0.0040 & 0.0000 \\
\hline Cumulative & 0.9960 & 1.0000 & 1.0000 \\
\hline
\end{tabular}

Table 8. Principal component for experimental trails

\begin{tabular}{|c|c|c|c|}
\hline Trails & VPC1 & VPC2 & VPC3 \\
\hline 1 & -0.2417 & 0.3499 & 0.7415 \\
\hline 2 & 0.3620 & 0.3611 & 0.6863 \\
\hline 3 & 0.1139 & 0.4801 & 0.6536 \\
\hline 4 & 0.6780 & 0.3730 & 0.7260 \\
\hline 5 & 0.6245 & 0.3946 & 0.6949 \\
\hline 6 & 0.5991 & 0.4414 & 0.6488 \\
\hline 7 & -0.4430 & 0.2929 & 0.7255 \\
\hline 8 & 0.1044 & 0.3535 & 0.6748 \\
\hline 9 & 0.6497 & 0.3689 & 0.6483 \\
\hline
\end{tabular}

Table 9. Total principal component index with ranks

\begin{tabular}{|c|c|c|}
\hline Trails & TPCI & Ranks \\
\hline 1 & -0.2393 & 8 \\
\hline 2 & 0.3620 & 5 \\
\hline 3 & 0.1153 & 6 \\
\hline $\mathbf{4}$ & $\mathbf{0 . 6 7 6 8}$ & $\mathbf{1}$ \\
\hline 5 & 0.6237 & 3 \\
\hline 6 & 0.5985 & 4 \\
\hline 7 & -0.4401 & 9 \\
\hline 8 & 0.1054 & 7 \\
\hline 9 & 0.6486 & 2 \\
\hline
\end{tabular}

ANOVA is conducted to identify the most significant factor which is affecting the performance and result of ANOVA is given in Table 10. It shows the individual affect with percentage contribution of Open voltage, Servo voltage \& Gap voltage. In our F-test, if $\mathrm{F}$ value of any input parameter is high, it means that input parameter is affecting most (following Gopalsamy et al., 2009). 
Table 10. ANOVA table

\begin{tabular}{|c|c|c|c|c|c|}
\hline Symbol & DOF & Sum of square & Variance & F-values & Contribution (\%) \\
\hline A & 2 & 0.586 & 0.293 & 12.466 & 42.96 \\
\hline B & 2 & 0.348 & 0.174 & 7.401 & 25.50 \\
\hline C & 2 & 0.383 & 0.192 & 8.151 & 28.09 \\
\hline Error & 2 & 0.047 & 0.023 & & 3.45 \\
\hline Sum & & & & & 100 \\
\hline
\end{tabular}

\section{Results and Discussion}

We consider Open voltage, Servo voltage \& Wire feed as our input parameters and material removal rate, machine timing, \& gap voltage as our responses. The experimental data is analyzed, using the PCA method with the aim to identify the optimum combination of machining parameters on which MRR is maximum at minimum MT and GV. Here, for MRR, higher-the-better criterion and for all machining time and Gap voltage parameters lower-the-better criterion have been carried out. According to $(\mathrm{H}$. Singh and R. Grag, 2009) normalization is done to decrease the variation between 0 to1. Responses are checked whether they were correlated or not using Pearson's correlation coefficient. Eigen value, Eigen vector, and accountability proportion (AP) are shown in Table 7. Finally, Total principal component index (TPCI) for each trail is computed which is in Table 9. We identify best process parameters $\left(\mathrm{A}_{2} \mathrm{~B}_{1} \mathrm{C}_{2}\right)$, means on 85 Open Voltage, 30 Servo Voltage and 6 Wire feed, machining will be optimum it will give maximum MRR at minimum MT and GV which is in Table 11.

Table 11. Optimal process parameters

\begin{tabular}{|c|c|c|c|c|c|c|}
\hline S. No. & Open Voltage & Servo Voltage & Wire Feed & $\begin{array}{c}\text { Material Removal } \\
\text { Rate }\end{array}$ & $\begin{array}{c}\text { Machining } \\
\text { Time }\end{array}$ & $\begin{array}{c}\text { Gap } \\
\text { Voltage }\end{array}$ \\
\hline 1 & 85 & 30 & 6 & 79.6000 & 5.1170 & 30.2000 \\
\hline
\end{tabular}

Individual optimal process parameters are identified and shown in Table 12. According to this optimal process parameters are $\left(\mathrm{A}_{3}\right.$ $\left.\mathrm{B}_{1} \mathrm{C}_{2}\right)$.

Table 12. Main effect of factors on the TPCI

\begin{tabular}{|c|c|c|c|c|c|}
\hline Inputs & Level 1 & Level 2 & Level 3 & Max-Min & Rank \\
\hline Open Voltage (OV) & 0.0794 & -0.0009 & $0.1549^{*}$ & 0.1558 & 3 \\
\hline Servo Voltage (SV) & $0.6330^{*}$ & 0.3637 & 0.5625 & 0.2693 & 1 \\
\hline Gap Voltage (GP) & 0.1046 & $0.4541^{*}$ & 0.0996 & 0.3545 & 2 \\
\hline
\end{tabular}

* Optimal values

\section{Conclusions}

Taguchi method of experimental design has been carried out for optimizing multi response parameters for wire EDM are optimized with $\mathrm{L}_{9}$ orthogonal array. Optimal parameters found for finish machining are 90 open Voltage, 30 Servo Voltage and 6 Wire feed. In these process parameters Open voltage is most affecting parameters. Percentage contribution was determined with the help of ANOVA. The conclusions of this experimental optimization work are summarized as follows:

- The experimental results were found with good agreement.

- The optimal parameters combination was identified as $\mathrm{A}_{3} \mathrm{~B}_{1} \mathrm{C}_{2}$ i.e. Open voltage $90 \mathrm{~V}$, Servo Voltage $30 \mathrm{~V}$ and wire feed $6 \mathrm{~m} / \mathrm{min}$.

- ANOVA shows the percentage contribution of individual parameters.

- The result of ANOVA shows affect of Open voltage is more, than other input parameters.

- ANOVA find out the $3.45 \%$ of error in experimental calculation. 


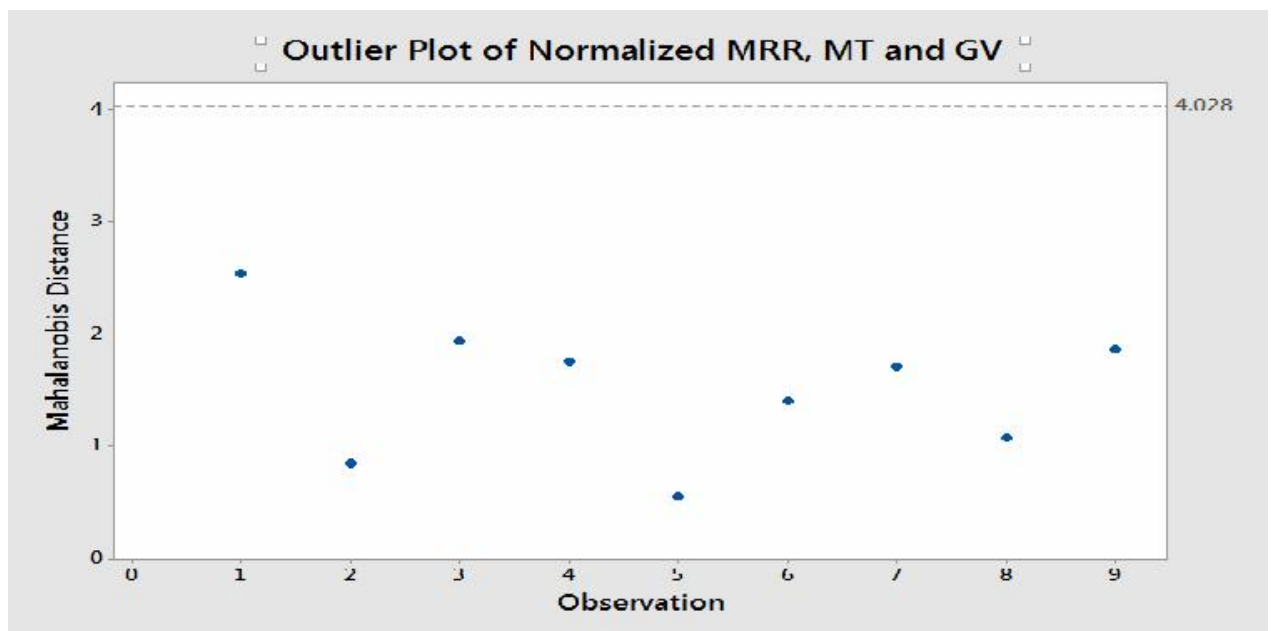

Figure 3. Normalized MRR, MT \& GV outer plot

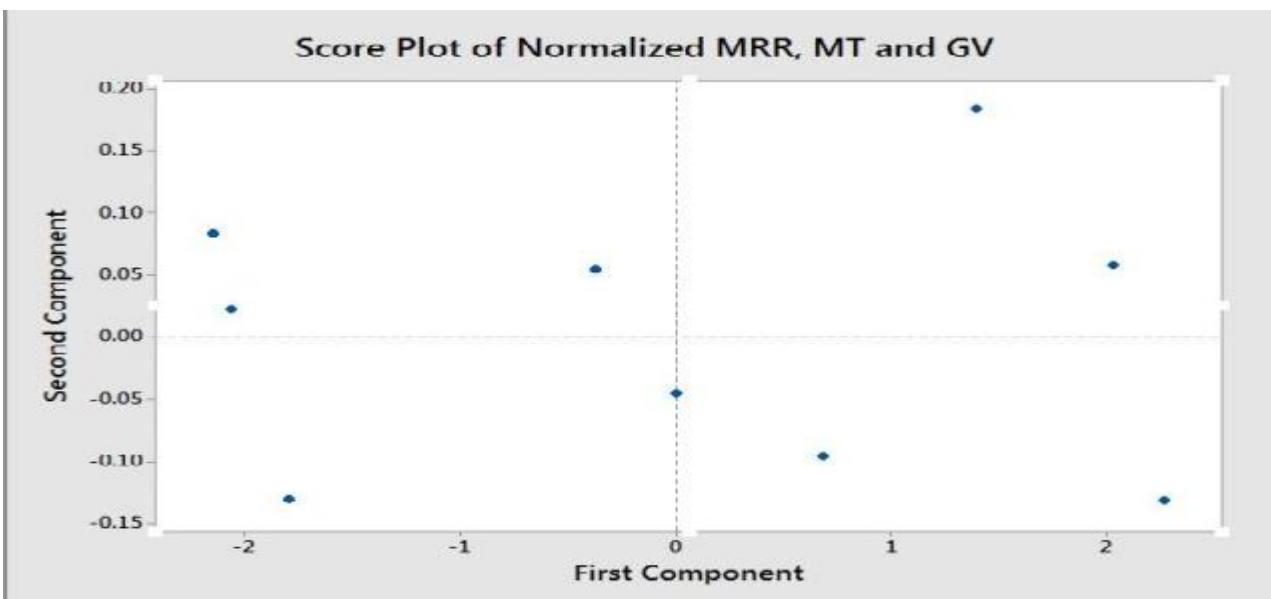

Figure 4. Normalized MRR, MT \& GV score plot

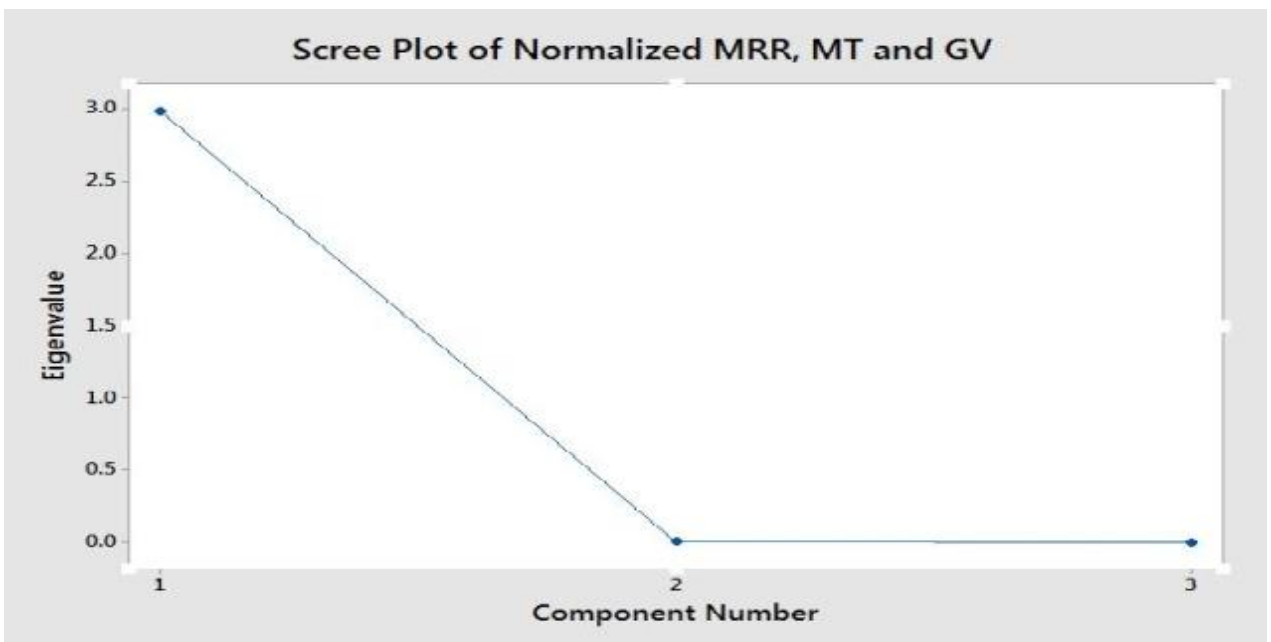

Figure 5. Normalized MRR, MT \& GV scree plot 


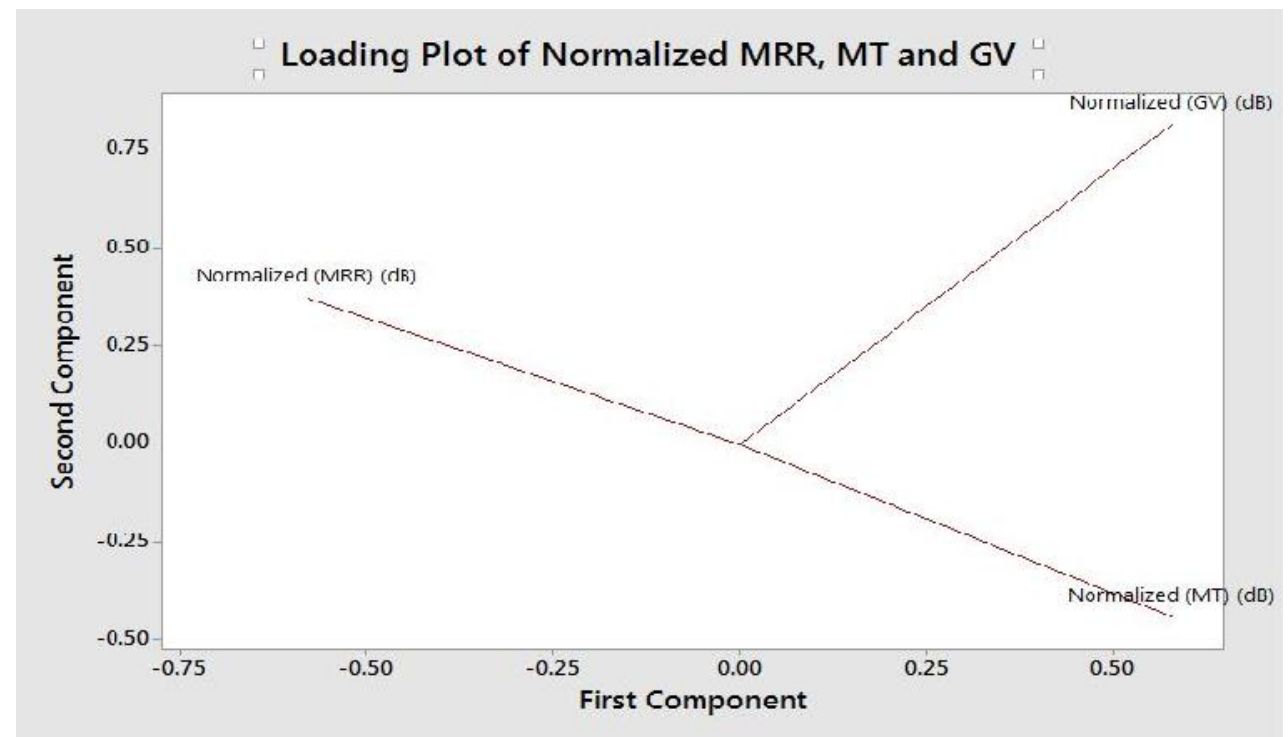

Figure 6. Normalized MRR, MT \& GV loading plot

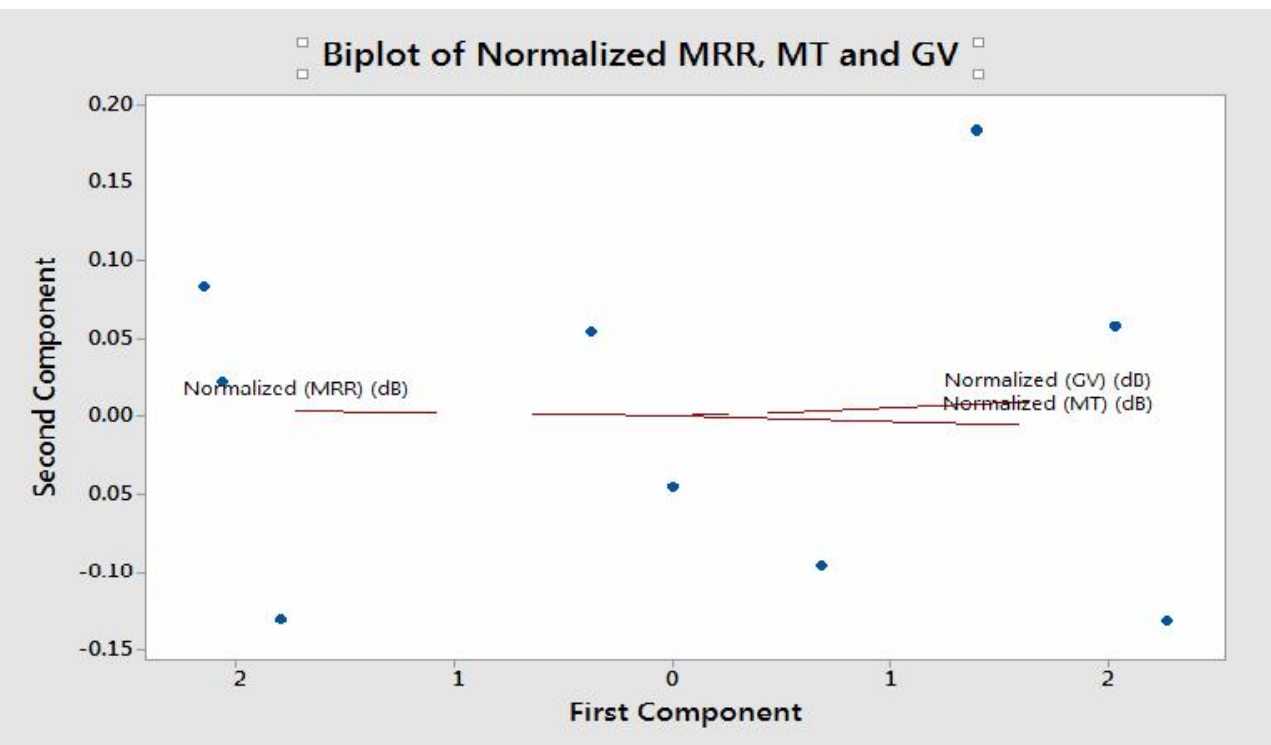

Figure 7. Normalized MRR, MT \& GV biplot plot

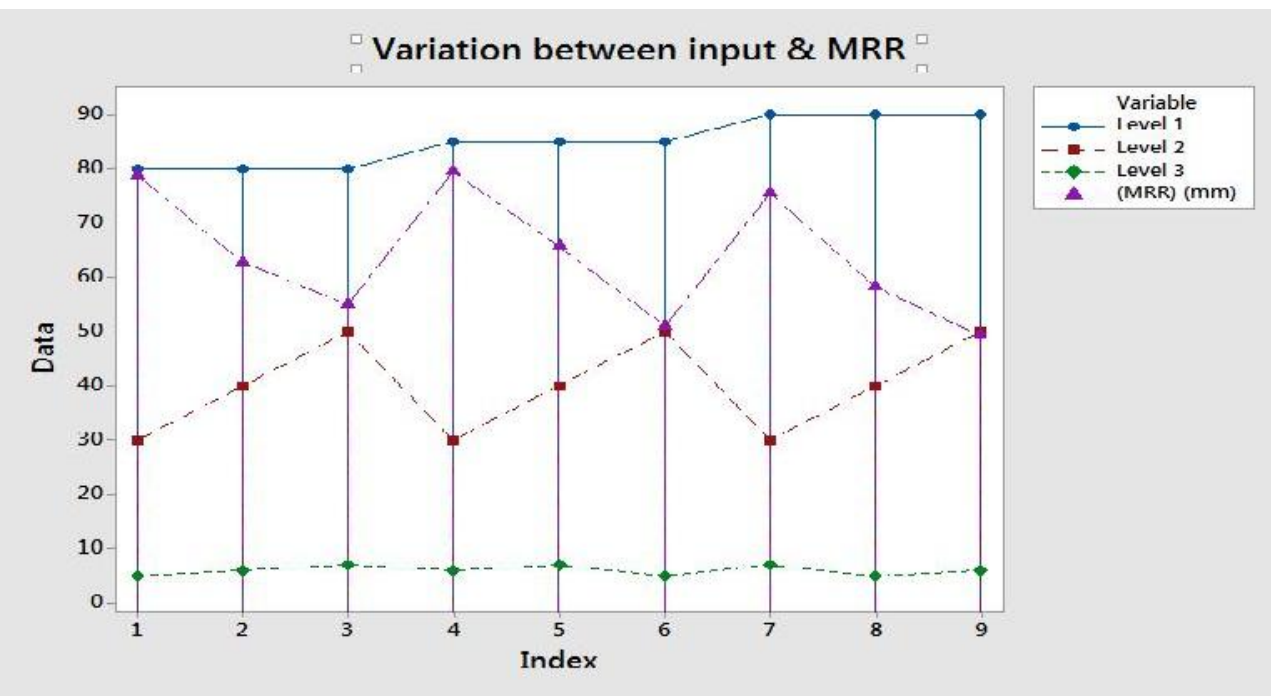

Figure 8. Variation between input values and MRR 


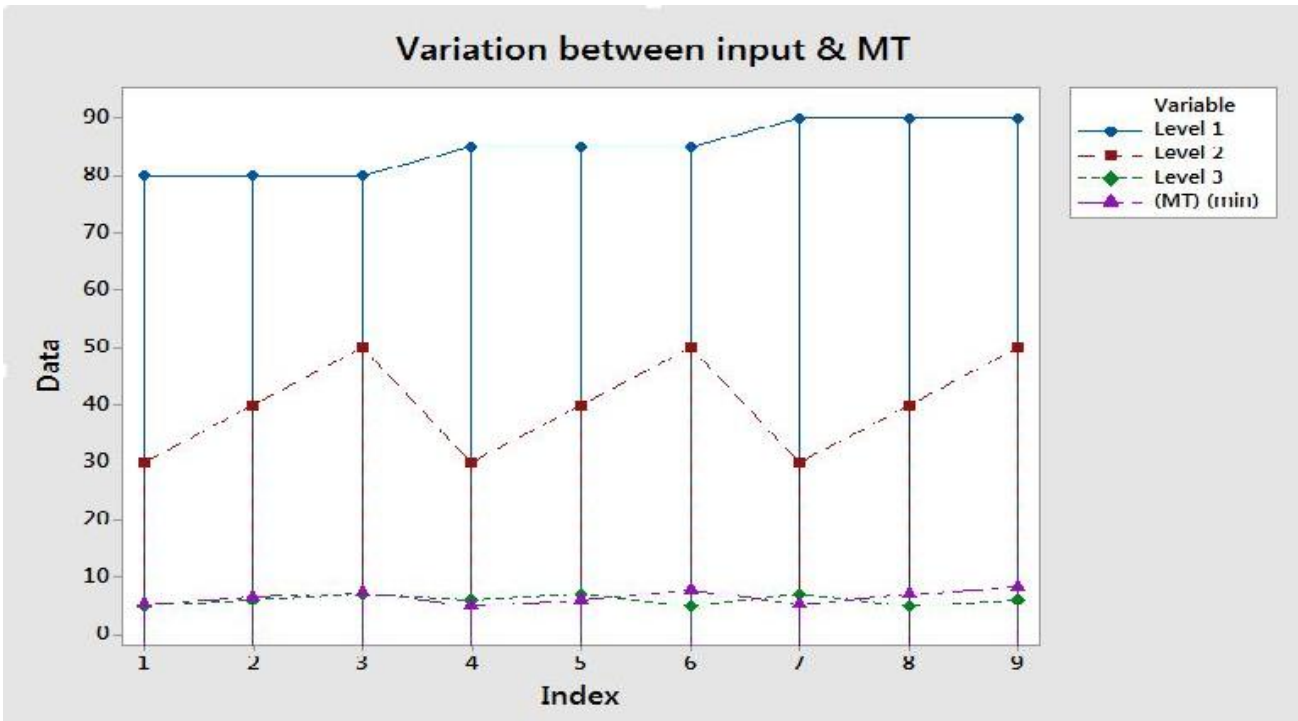

Figure 9. Variation between input values and MT

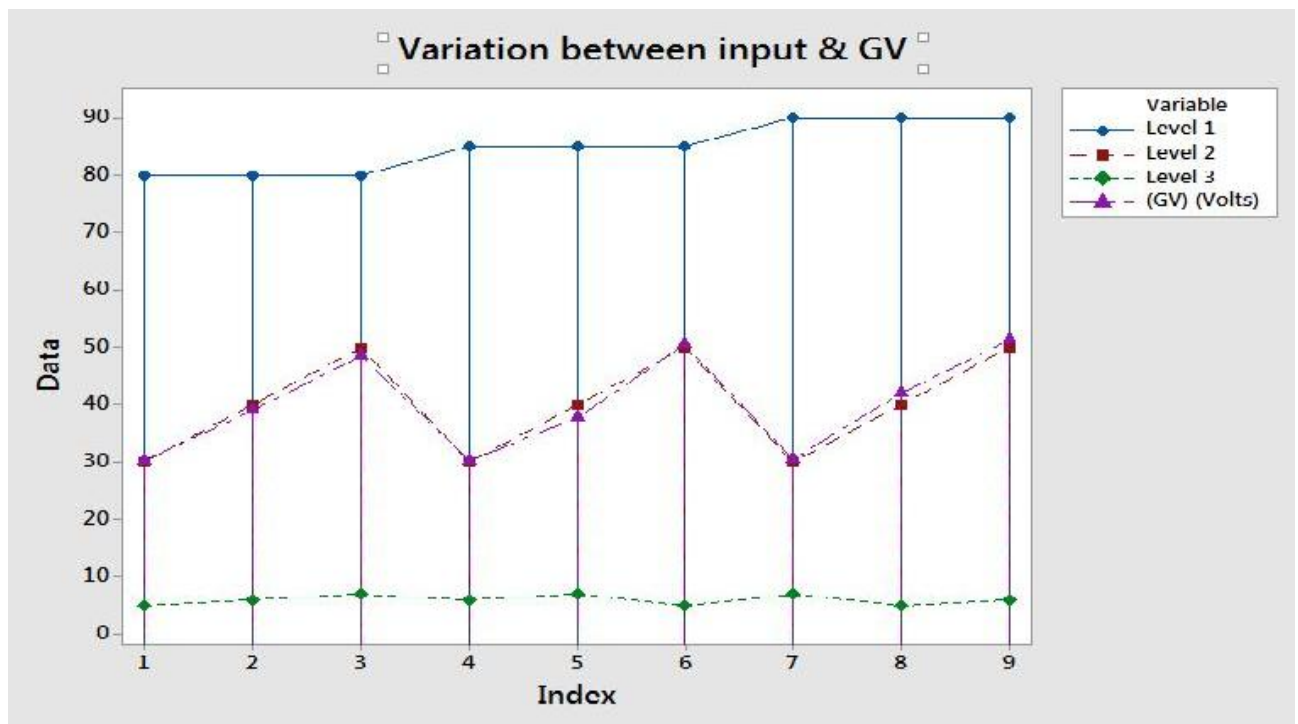

Figure 10. Variation between input values and GV

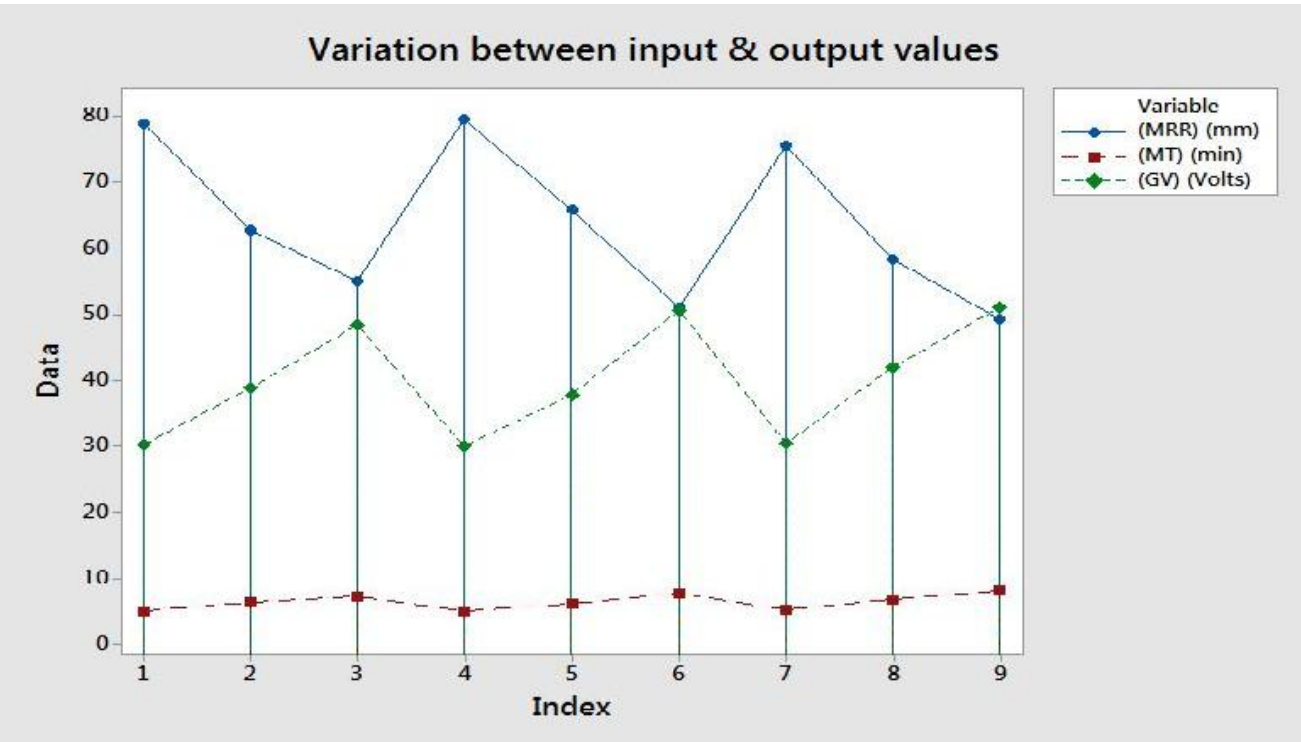

Figure 11. Variation between input \& output values 


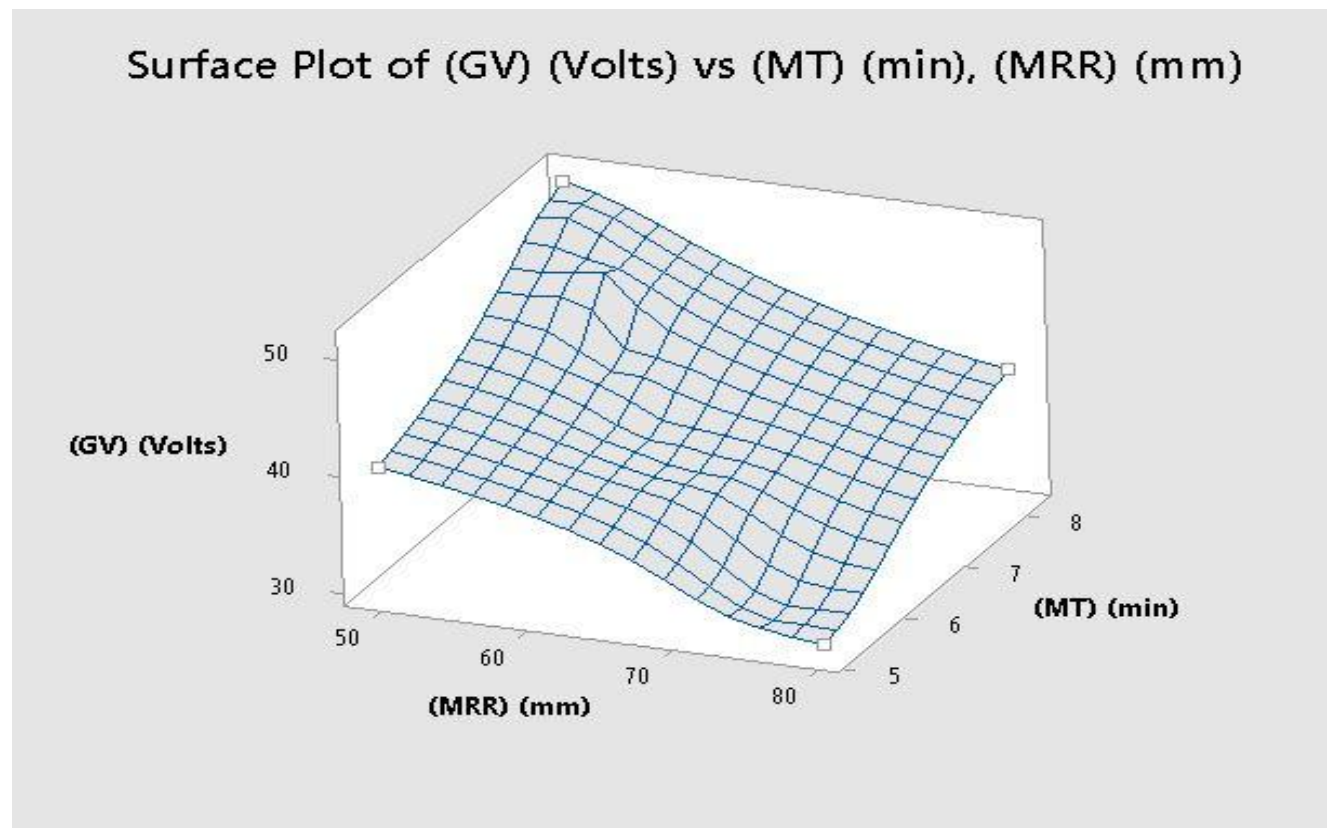

Figure 12. Surface plot of responses

\section{Surface Plot of (GV) (Volts) vs (MT) (min), (MRR) (mm)}

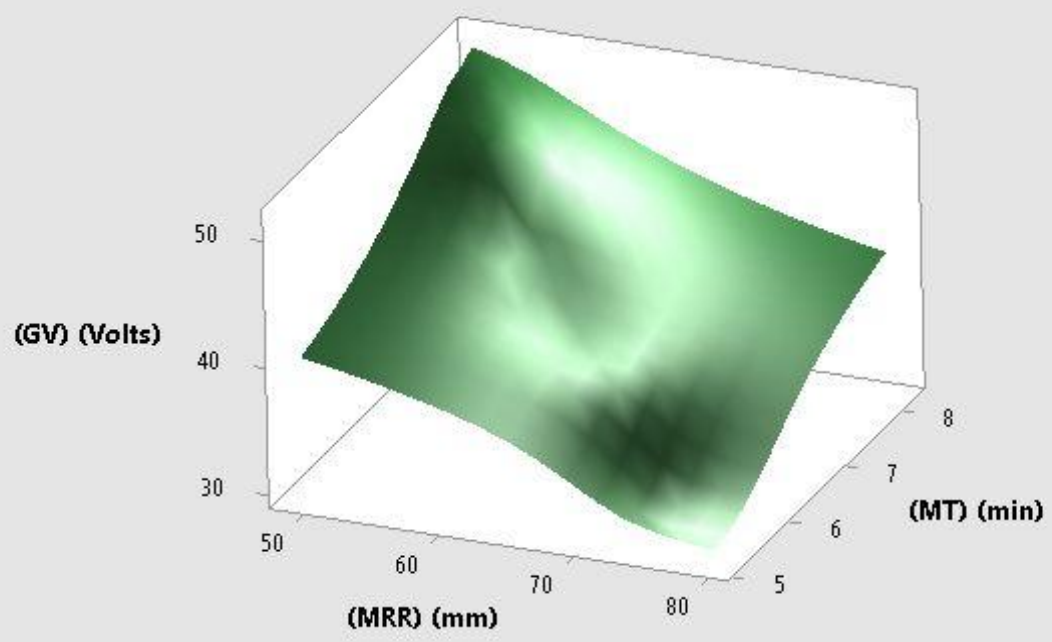

Figure 13. Surface plot of responses

\section{Nomenclature}

$\begin{array}{ll}\mathrm{X}_{\mathrm{uv}} & \text { The } v \text { th response of the } u \text { th experiment } \\ \mathrm{X}_{\mathrm{uv}} & \text { Normalized S/N ratio of the } u \text { th performance characteristic in the } v \text { th experiment } \\ \mathrm{Z} & \text { Normalized array } \\ \operatorname{Cov}(\mathrm{x}(\mathrm{u})) & \text { Covariance of sequence } \mathrm{x}(\mathrm{u}) \\ \operatorname{Cov}(\mathrm{x}(\mathrm{v})) & \text { Covariance of sequence } \mathrm{x}(\mathrm{v}) \\ \operatorname{Var}(\mathrm{x}(\mathrm{u})) & \text { Variance of } \mathrm{x}(\mathrm{u}) \\ \operatorname{Var}(\mathrm{x}(\mathrm{v})) & \text { Variance of } \mathrm{x}(\mathrm{v}) \\ \mathrm{R}_{\mathrm{uv}} & \text { Correlation coefficient array } \\ \lambda_{\mathrm{x}} & \text { Eigen values } \\ \mathrm{V}_{\mathrm{uv}} & \text { Eigenvectors corresponding }\end{array}$




\section{References}

Chandgude S.B., Pawar P.J., Sadaiah M., 2015. Process parameter optimization based on principal components analysis during machining of hardened steel. International Journal of Industrial Engineering Computation Vol. 6, pp. 379-390

Chalisgaonkar R., Kumar J., 2014. Multi-response optimization and modeling of trim cut WEDM operation of commercially pure titanium (CPTi) considering multiple users' preferences. International Journal of Engineering Science and Technology Vol. 18 , pp. $125-134$

Das M.K., Kumar K., Barman T.K., Sahoo P., 2014. Optimization of WEDM process parameters on EN31steel by weighted principal component analysis. IOSR Journal of Mechanical and Civil Engineering, pp. 30-33

Dharmender, R.K., Bhatia A., 2012, Investigation of the effect of process parameters on surface roughness in wire electric discharge machining of En31 tool steel, Proceedings of the National Conference on Trends and Advances in Mechanical Engineering, YMCA University of Science \& Technology, Faridabad, Haryana, pp. 417-423.

Durairaj M., Ansari A. K. S., Gauthamkumar M. H., 2014. Parametric optimization of wire cut electrical discharge machining. International Journal of Engineering \& Technology Vol. 3, pp. 212-215

Ghodsiyeh D., Golshan A., Shirvanehdeh J.A., 2013. Review on current research trends in wire electrical discharge machining (WEDM). Indian Journal of Science and Technology Vol. 6, pp. 4128-4140

Gopalsamy B.M., Mondal B., Ghosh S., 2009. Taguchi method and ANOVA: An approach for process parameters optimization of hard machining while machining hardened steel. Journal of Scientific \& Industrial Research Vol. 68, pp. 686-695

Gupta S.K., Pandey K. N., Kumar R., 2015. Optimization of friction stir welding process parameters using hybrid approach for joining of dissimilar aluminium alloys. International Conference on Advances in Material, Manufacturing and Application, pp. 749-754.

Hotelling H, 1933, Analysis of a complex of statistical variables into principal components. Journal of Education Psychology Vol. 24, pp. 417-441

Jaiganesh V., Raju R., 2008, Multiple response optimization of wire electrical discharging machining process parameters. International Journal of Advanced Engineering Applications, Vol. 1, pp. 23-27

Kumar N., Malhotra N., Sharma S. K., 2015. Review on current research work in wire electrical discharge machining. International Journal of Advance Research and Innovation Vol. 3, pp. 68-76

Lahane S.D., Rodge M.K., Sharma S.B., 2012, Multi-response optimization of Wire-EDM process using principal component analysis. IOSR Journal of Engineering Vol. 2, pp. 38-47

Lokesh R., Senthilkumar V. S., Rathinasuriyan C., and Sankar R., 2015, Optimization of process parameters: tool pin profile, rotational speed and welding speed for submerged friction stir welding of aa6063 alloy. International Journal of Technical Research and Application, pp. 35-38

Mohapatra K. D., Sahoo S. K., 2015a. Micro-Structural analysis and multi-objective optimization in gear cutting process for AISI 304 stainless steel using wire EDM. IRF International Conference Pune, pp. 98-103

Mohapatra K.D., Sahoo S. K., 2015b. Experimental investigation of wire EDM parameters for gear cutting process using desirability with PCA, International Journal For Technological Research In Engineering vol. 2, pp. 2415-2419

Nayak B.B., Mahapatra S.S., 2014, A neuro-fuzzy approach for optimizing of multiple responses in taper cutting using wire electrical discharging machining, International conference on All India Manufacturing Technology, Design and Research, Vol. 180, pp. 1-6

Paiva A.P., Ferreira J.R., Balestrassi P.P., 2007, A multivariate hybrid approach applied to AISI 52100 hardened steel turning optimization. Journal of Materials Processing Technology 189, pp. 26-35

Pearson K, 1901, Lines and planes of closest fit to system of points in spaces. Philos Mag Ser Vol. 62, pp. 559-572

Paul L.C., Al-Sumam A., 2012. Face recognition using principal component analysis method. International Journal of Advanced Research in Computer Engineering \& Technology Vol. 1, pp. 135-139

Prajapati S. B., Patel N.S., 2013, Effect of process parameters on performance measure of wire EDM for AISI A2 tool steel. International Journal of Computational Engineering Research Vol. 3, pp. 274-278

Rajyalakshmi G., Venkata P.R., 2013, Optimization of process parameters of wire electrical discharge machining using fuzzy logic integrated with Taguchi method. International Journal of Scientific Engineering and Technology Vol. 2, pp. 600-606

Raghuraman S, Thiruppathi K, Panneerselvam J, Santosh S, 2013. Optimization of EDM parameters using Taguchi method and Grey relational analysis for mild steel IS 2026. International Journal of Innovation Researcher in Science Engineering and Technology Vol. 2, pp. 3095-3104

Rao T.L., Selvaraj N., 2013, Optimization of WEDM process parameters on Titanium alloy using Taguchi method. International Journal of Modern Engineering Research Vol. 3, pp. 2281-2286

Singh J., Sharma S., 2013. Effects of process parameters on material removal rate and surface roughness in WEDM of P20 tool steel. International Journal of Multidisciplinary and Current Research Vol. 1, pp. 230-235

Siddiquee A.N., Khan Z.A., Mallick Z., 2009. Grey relational analysis coupled with principal component analysis for optimization design of the process parameters in in-feed centreless cylindrical grinding. The International Journal of Advanced Manufacturing Technology, Vol.46, No. 9, pp. 983-992

Singh H. and Grag R., 2009, Effect of process parameters on material removal rate in WEDM. Journal of Achievement Material Manufacturing Engineering Vol. 32, pp. 70-74 


\section{Biographical notes}

Anil Kumar Dhakad completed his Bachelor of Engineering in Mechanical Engineering (M.E.) form NRI institute of Technology and management (NRIITM) Gwalior, India, in 2014. Currently, he is a research scholar in Madhav Institute of Technology \& Science, Gwalior, India. He has one research paper on Wire EDM. His research interest includes Production, Electrical discharge machine and Optimization of process parameters for Wire electrical discharge machine.

Jyoti Vimal is an Assistant Professor in the Department of Mechanical Engineering, in Madhav Institute of Technology \& Science Gwalior, India. He received B.E. (Mechanical Engineering) form GBPEC, Pauri, Garhwal, M. Tech from HBTE, Raipur and Ph.D. from National Institute of Technology, Allahabad. He has 8 years teaching experience and 2 years research experience.

Received May 2016

Accepted September 2016

Final acceptance in revised form May 2017 